УДК 159.9.072.43

\title{
ЦЕННОСТИ СЕМЬИ КАК ФАКТОР ЭТНОКОНФЕССИОНАЛЬНОЙ БЕЗОПАСНОСТИ
}

\author{
Звездина Галина Павловна \\ Исмаилов Казбек Ваитович
}

В статье обоснована актуальность изучения проблемы этноконфессиональной безопасности поликультурного региона в современном российском обществе. Проведена дифференциация понятий, относящихся к проблеме этноконфессиональной безопасности. Рассмотрены особенности презентации понятий: конфессиональная безопасность, религиозная безопасность, этнокультурная и этническая безопасность, этноконфессиональная безопасность. Обозначены угрозы этноконфессиональной безопасности в условиях ситуации неопределенности и нестабильности современного социума. Показана роль семьи как социального института общества, транслирующего ченности культуры и традиций своего этноса. Представлены результаты эмпирического изучения семейных ченностей супружеских пар разной этнической принадлежности, проживающих в условиях поликультурного региона (Чеченская Республика). Выделены и описаны особенности ценностей современной семьи, в зависимости от этнической принадлежности (русские, чеченцы, смешанные семьи), в контексте этноконфессиональной безопасности.

Выявлено, что для семей этнических русских значимыми являются ченности благополучия: иметь хорошую работу и хорошую семью, здоровье, быть любимыми. Большинство респондентов высказали необходимость поддерживать национальные традиции, прививать народные ченности и традиции своим детям. Установлено: в смешанных семьях большая часть респондентов обоего пола отметили, что поддерживать национальные традиции и развитие национальной культуры, прививать народные ченности и традиции своим детям, жить духовной жизнью для них важно; система оценок респондентов находится в диапазоне высоких и выше среднего. Выявлено, что в этнических чеченских семьях отмечается важность передачи своим детям народных традиций, формирующих и поддерживающих чувство единения на уровне этноса, общины, семьи, позволяющих отдельному индивиду осознать свою этническую принадлежность, сохраняющих вековые ценностные ориентации и установки.

Ключевые слова: поликультурный регион, конфессиональная безопасность, религиозная безопасность, этноконфессиональность, этническая безопасность, этноконфессиональная безопасность, ченности семьи, иенности безопасности. 
Проблема безопасности поликультурного мира становится актуальной на фоне трансформационных и глобализационных процессов, происходящих в современном мире. Любой поликультурный регион полиэтничен и поликонфессионален по определению. И это, наряду с многоголосием и многоаспектностью культурной жизни страны, ее отдельных регионов создает целый ряд точек напряженности и рисков, актуализируя тем самым проблему безопасности. Этноконфессиональный фактор в современной социальной практике осознается в качестве важнейшего и необходимого слагаемого поддержания целостности и жизнеспособности общества, его безопасности.

Особый интерес вызывает исследование проблем безопасности тех регионов Российской Федерации, которые характеризуются нестабильностью ситуации, этноконфессиональным многообразием состава населения, находятся в зоне геополитических интересов ряда зарубежных государств. К таким регионам относится и Северный Кавказ, от стабильности и устойчивости развития которого в прямой зависимости находится уровень обеспечения безопасности всей Российской Федерации.

Россия - многонациональное государство, и характер складывающихся отношений между различными этническими и конфессиональными группами во многом определяет общественно-политическую стабильность в государстве. Этноконфессиональная безопасность является частью, прежде всего, национальной безопасности. Среди факторов и угроз, оказывающих негативное влияние на обеспечение национальных интересов России, в «Стратегии национальной безопасности Российской Федерации до 2020 г.» не случайно выделяется развитие националистических настроений, ксенофобии, сепаратизма и насильственного экстремизма, в том числе под лозунгом религиозного радикализма [16].

Термин «этноконфессиональная безопасность» до сих пор еще недостаточно определен в современной науке. Остановимся на том, что выделяются разные виды безопасности в контексте этнических и конфессиональных отношений. В отечественной научной и публицистической литературе часто встречаются два на первый взгляд взаимозаменяемых, а в ряде случаев и подменяемых понятий - «конфессиональная безопасность» и «религиозная безопасность». Однако, как не тождественны сами понятия конфессии и религии, так и не тождественны понятия религиозной и конфессиональной безопасности.

Понятие религиозной безопасности чаще всего употребляется в отечественной литературе православного характера, в основном в контексте защиты традиционной православной религии от современных нетрадиционных культов, имеющих экстремистский характер. Современные теологи 
создают механизмы защиты от вступления молодежи в подобные секты [9]. Система этих механизмов и является основой таким образом понимаемой религиозной безопасности. В светской отечественной научной литературе введение понятия религиозной безопасности подразумевает безопасность традиционных религий и их защиту, прежде всего от нетрадиционных религиозных культов [6].

Термин «конфессиональная безопасность» является относительно новым для отечественной науки, хотя уже достаточно используется в научном обороте (П. Н. Беспаленко, А. Т. Гилалов, Р. Кадыржанов, Ю. Г. Карпухин, А. Нысанбаев, А. И. Шустева).

Исследователи подчеркивают значение конфессионального фактора в системе общенациональной безопасности, отмечая, что «можно говорить об особом аспекте безопасности, который непосредственно связан с высоким уровнем конфессиональной напряженности» [8].

Понятие «конфессиональная безопасность» охватывает и межконфессиональные проблемы, и личную безопасность, и духовную безопасность, а также сохранение религиозной идентичности не только на национальном, но и на личностном уровне [17].

Помимо понятия «конфессиональная безопасность» в литературе встречается использование понятия «этническая безопасность». Под этнической безопасностью понимается «безопасность общественной жизни, в которой нет места национальной розни, национальной нетерпимости, в которой право не выделяет в качестве приоритета национальную принадлежность и применяется ко всем национальностям объективно и справедливо, согласно букве закона» [15].

В рамках социокультурного подхода отдельно выделяется этнокультурная безопасность. Отечественные исследователи Л. С. Перепелкин и В. Г. Стельмах в определении понятия «этнокультурная безопасность» обращают внимание на проблемы взаимодействия представителей разных этнокультурных групп, проживающих на территории Российской Федерации. Согласно пониманию авторов, «этнокультурная безопасность - это сфера устойчивого функционирования и воспроизводства культур всех национальных групп, проживающих в рамках того или иного государства, вкупе с возможностью их участия в свободном взаимообмене культурными ценностями и сохранения их членами своей этнической идентичности» [11].

Так как предметом нашего исследования является этноконфессиональная безопасность, остановимся более подробно на данной проблеме.

Исследователь К. Аллахвердиев отмечает, что «в отличие от этнической и конфессиональной сфер, этноконфессиональность не является самостоятельным субстратом жизни народа. Этноконфессиональность, обусловленная 
исторически развивающейся сопряженностью этих сфер, представляет собой качественно новую социоантропогенную идентичность, создающую фоновую социально-психологическую среду, в которой происходит дальнейшее структурирование этноса путем этнонациональной имплементации религии, трансляции конфессионального содержания в этнические формы, конструирования новых системных компонентов социальной жизни этноса» [2].

Этноконфессиональная безопасность представляет собой основу национальной безопасности, она может быть представлена как система государственных гарантий и поддержки духовного потенциала народов и наций. Этноконфессиональная безопасность понимается как «система сохранения контентного содержания любой конфессии и ее культовой оболочки, а также этнической идентичности, так и предотвращение конфликтов на конфессиональной и этнической почве. Этноконфессиональная безопасность - это система условий для полноценного развития различных конфессий в едином культурном пространстве, предотвращающая или, по крайней мере, смягчающая конфликты, связанные с этноконфессиональной принадлежностью» [14].

Актуализация этноконфессиональной безопасности и возрастание роли этничности в современных условиях является естественной реакцией на так называемый эффект неопределенности современной реальности, ее высокую противоречивость.

Растущее осознание мировой общественностью обострения противоречия между повышением уровня полиэтничности социальной среды, в которой живет и трудится человек, и его неподготовленностью к изменяющимся условиям жизни выдвигает на первый план стратегических направлений развития образования поликультурное образование и воспитание подрастающих поколений [19].

Миропонимание человека, которое складывалось в результате воспитания в семье, традиционного образования и воздействия средств массовой информации, не соответствует тем условиям жизни, в которые погружается общество в новой, постиндустриальной эпохе [5]. Возникает некое противоречие между необходимостью постоянно изменяться и необходимостью сохранения этнической уникальности и устойчивости современного мира и тех ценностей, которые определяют жизненные выборы современного человека.

Нестабильность жизни, отсутствие социальных гарантий, расслоение общества, смена культурных ценностей повлекли за собой коренные изменения в личностных смыслах и ценностях человека, обострили явные и скрытые противоречия, имеющиеся в современном обществе. Нарастание деструктивных социокультурных изменений выступает в качестве угрозы 
этноконфессиональной безопасности, находит реальное воплощение в актах терроризма и экстремизма, особенно в молодежной среде.

Этноконфессиональная безопасность базируется на воспитании, основанном на традиционных ценностях, таких как: любовь к человеку, дружба народов, трудолюбие, патриотизм, коллективизм, прочность семейных устоев, моральная чистота. Основу данного процесса составляет этика толерантности.

Семья является наиболее полноценной микросредой для формирования личности. Об этом свидетельствуют и широкие опросы, в том числе и в среде молодежи [12]. Семья - уникальный и пока единственный социальный институт воспитания, воспроизводящий людей как носителей социальной, культурной, этнонациональной по специфике содержания информации, транслируемой по поколениям [7].

Семья в сущности своей содержит все институции социального характера. Семья как институт не просто взаимодействует с ними, на основе законов всеобщей связи всех переменных, образующих общество, но и все они в неразвитой форме, в источнике, в потенции даны в сущности семьи. Поэтому семья не существует вне социальных институтов, как и они не существуют вне семьи. Общество у всех народов, наций, племен, во всех частях мира и во все времена состояло и состоит из семей, а не непосредственно из личностей. Семейные отношения, в которых переплетаются природные и социальные факторы, занимают в системе человеческих отношений особое место своим постоянством, многообразием и разнообразием субъектов, и передачей от поколения к поколению наследственных свойств, влияющих на формирование характера и психологии индивидов.

Взаимодействие семьи с другими социальными институтами происходит не иначе как через закон согласования. Семейные и родственные отношения свободно распространяются на людей с различным имущественным положением, социально-классовым, мировоззренческим, нравственно-культурным, даже этническим и конфессиональным миром. Этим свойством они смягчают социальные и другие противоречия в обществе, способствуют формированию толерантных отношений.

Современная семья, как и другие социальные институты общества, переживает трансформацию, в рамках которой происходит изменение семейных ценностей и установок населения (в первую очередь, молодежи), характера отношений и образа жизни современной российской семьи.

Предметом нашего исследования выступили особенности семейных ценностей современных семей разной этнической принадлежности, проживающих в условиях поликультурного региона (Чеченская Республика), в контексте этноконфессиональной безопасности. 
В социально-психологическом исследовании приняли участие 60 респондентов, которые были представлены тремя группами: русские семьи - 10 семейных пар, 10 мужчин и 10 женщин, соответственно 10 семейных пар чеченцев и 10 смешанных семейных пар (муж - чеченец, жена - русская или другая национальность).

Изучение жизненных целей и ценностей в разных выборках респондентов показало свою специфику. В этнически русских семьях среди значимых целей и ценностей, выдвигаемых мужчинами и женщинами, находятся цели благополучия: иметь хорошую работу и хорошую семью, здоровье, быть любимым. Также среди значимых целей находятся: материальный достаток, желание овладеть определенной профессией и мастерством. В данной выборке наблюдаются определенные и гендерные различия: так 40 \% мужчин в качестве значимой ценности высказали «не стать алкоголиком и наркоманом»; 60 \% мужчин отметили ценность «не стареть» как незначимую, не имеющую для них ценности. Среди незначимых, как у мужчин, так и у женщин, находятся: «навсегда уехать за границу», «изменить свою жизнь». Однако женщины в большей степени ориентированы на саморазвитие и понимание смысла жизни, для них более важно «сделать себя таким, каким хочу».

При изучении религиозной идентичности было выявлено: большинство мужчин и женщин этнически русских отметили, что посвятить свою жизнь Богу скорее для них не важно, чем важно, 15 \% высказали, что жить духовной жизнью, вести добропорядочную нравственную жизнь для них совсем не важно. Также к стагнирующим ценностям для некоторой части выборки (30\%) относится желание поддерживать национальные традиции, прививать народные ценности и традиции своим детям.

По мнению исследователя Л. П. Ипатовой, религиозная идентичность очень часто является маркером культурной идентичности. Социологические исследования показывают, что за «самоидентификацией себя в качестве православного в ряде случаев стоит не исповедание веры, не принятие православного образа жизни, а исключительно признание Православия в качестве исторически сложившейся в нашей стране культурной традиции», о чем свидетельствуют и результаты нашего исследования [5].

Ценности развития и творчества не относятся к значимым в данной выборке респондентов и в иерархии ценностей занимают более низкие позиции, что в большей степени говорит о традиционализме семейных ценностей, о необходимости сохранять традиции и нормы поведения в изменяющихся условиях общества.

Изучение ценностных приоритетов в смешанных семьях (чеченцы и русские) показало, что 70 \% мужчин и 50 \% женщин в качестве ведущей назвали ценность «посвятить свою жизнь Богу». Среди ведущих ценностей также названы 
следующие: «достойно умереть», «иметь хорошую семью», «обеспечить счастье своих детей», «не служить в армии». Около 20 \% респондентов мужского пола в качестве значимых отметили «не стать алкоголиком и наркоманом», тогда как в предыдущей выборке важным для себя отметили это 40 \% мужчин.

Наименее важной ценностью для значительной части мужчин данной выборки (60 \%) является «навсегда уехать за границу», они в большей степени предпочитают жить и работать на родине. Для 20 \% мужчин не актуальна проблема старения и путешествия по всему миру.

У женщин данной выборки наблюдается больший разброс в ценностных приоритетах: «не голодать», «не стать жертвой преступлений», «добиться, чтобы тебя ценили и уважали», «быть любимой», «вести добропорядочную нравственную жизнь». Тогда как в качестве незначимых ценностей отмечены: «иметь хорошую работу», «быть смелым и решительным», «сделать карьеру», «делать все, что хотите», «не выделяться». Возможно, данный факт можно объяснить тем, что более 60 \% женщин данной выборки - неработающие домохозяйки, поэтому для них не является ценной потребность в профессиональной самореализации.

Интересным, на наш взгляд, является обращение к этнокультурным особенностям современной японской семьи. Сегодня воспитание детей является основной «работой» японских женщин. Для этого они получают соответствующее образование, чтобы передавать образцы воспитания своим детям [19]. Согласно результатам нашего исследования, данная тенденция, ориентированная на воспитание детей и отказ от карьеры, более свойственна женщинам из чеченских и смешанных семей.

Интересный факт был выявлен в данной выборке: определяя для себя значимой ценность «добиться, чтобы вас понимали, ценили и уважали», одновременно возводится в ранг незначимых «быть честным и порядочным». Такие качества, как честность и порядочность, входят сегодня в разряд стагнирующих.

Более 70 \% респондентов обоего пола отметили, что поддерживать национальные традиции, поддерживать развитие национальной культуры и традиций, прививать народные ценности и традиции своим детям, жить духовной жизнью для них важно; система оценок находится в диапазоне от «очень важно» до «скорее важно, чем не важно».

Отношение к изменению своей жизни примерно такое же, что и в предыдущей группе, однако многие отметили данную цель как важную для своих детей.

Таким образом, по данной выборке респондентов можно сделать следующие выводы: в большей степени представлены религиозные и традиционные ценности, достаточно выражена потребность в безопасности - «не голодать», «не стать жертвой преступлений» и др. 
Ценностная картина в семьях этнических чеченцев демонстрирует, что 90 \% супругов обоего пола высказывают желание посвятить свою жизнь Богу, $10 \%$ респондентов отметили важными ценности «достойно умереть», «понять смысл жизни». Позиция «добиться, чтобы вас понимали, ценили и уважали» присутствует у мужчин и женщин, но эта ценность важна для большего количества женщин - 30 \% против 10 \% у мужчин. Среди приоритетов женщин достаточно четко просматриваются ценности самореализации: «заниматься своим делом», «ни от кого не зависеть», «стать очень богатой», «сделать себя таким, каким хочу быть», «добиться, чтобы родители не мешали», «быть любимой», «жить духовной жизнью».

У мужчин в качестве приоритетов выступают: «быть смелым и решительным», «быть честным и порядочным человеком», «иметь хороший характер», «иметь хорошую работу», «обеспечить счастье своих детей». В качестве защитных потребностей у них выделены: «не голодать» и «не стать алкоголиком и наркоманом». У мужчин по ценностям, вошедшим в ранг незначимых, наблюдается разброс, 20 \% респондентов отметили для себя не важным «вести уединенную жизнь», и соответственно по 10 \% набрали: «входить в элиту общества», «найти настоящую любовь», «не стать жертвой преступлений». В ранг незначимых у мужчин и женщин данной группы вошли следующие ценности: «никому не завидовать», «не стареть» (30\% женщин), «путешествовать по миру».

Что касается вопроса «поддержка национальных традиций и национальной культуры», то здесь наблюдается следующая картина: 65 \% респондентов обоего пола считают это очень важным, по 10 \% считают, что «скорее важно, чем не важно» и «не то, чтобы важно, не то чтобы нет», и 5 \% считают - «совсем не важно». Несколько иная картина наблюдается по позиции: «прививать народные ценности и традиции своим детям». В формировании личности ребенка большое значение имеет практическое использование обрядов и ритуалов, регулирующих эмоциональное состояние людей, формирующих и поддерживающих чувство единения на уровне этноса, общины, семьи, позволяющей отдельному индивиду осознать свою этническую принадлежность, сохраняющих вековые ценностные ориентации и установки.

Из всей выборки респондентов чеченских семей $80 \%$ мужчин и $60 \%$ женщин однозначно считают, что это делать необходимо, 30 \% женщин и 10 \% мужчин придерживаются такой же точки зрения, но не в столь категоричной форме, и по 10 \% мужчин и женщин считают данную позицию совсем не важной.

Проведенный анализ результатов эмпирического исследования показал, что этнические ценности связаны с этноконфессиональными и являются больше этическими ценностями, передаваемыми с помощью механизма традиции, которая обеспечивает существование культуры этноса. 
В качестве одного из важных условий поддержания этноконфессиональной безопасности в поликультурных регионах является «создание эффективной системы просвещения граждан в части культурного и конфессионального многообразия, исторического единства жителей страны, истории религиозной нетерпимости, геноцида и других преступлений, порожденных экстремизмом и терроризмом» [1, с. 18].

Подобная работа, с одной стороны, позволит понять уникальность каждой культуры и этноса, с другой - увидеть общее и объединяющее всех народов, живущих на одной территории. В последнее десятилетие в науке появилась перспектива более объективного и глубокого изучения традиционной культуры и, в частности, представителя конфессии как носителя культурных норм и ценностей.

На основе проведенного теоретического анализа изучаемой проблемы и ее эмпирического исследования, можно констатировать, что в современных российских семьях разной этноконфессиональной направленности, несмотря на имеющиеся различия, имеет место единая система традиционных семейных ценностей, где семейное благополучие, любовь, взаимопонимание, благополучие детей, здоровье являются основополагающими. Потребность в безопасности (личной, экономической, политической), находящая свое выражение в ценностях, условно обозначаемых нами как «ценности безопасности», или материалистические ценности, характерна для всех представителей семей, вне зависимости от возраста и конфессиональной принадлежности. Данное положение является крайне существенным, поскольку, с одной стороны, является индикатором существования в нашей стране глубинных кризисных явлений экономического и социально-политического характера, а с другой определяет ценностный контент российского политико-культурного поля, о чем свидетельствуют данные проведенного социально-психологического исследования.

\section{Литература}

1. Абакумова И. В., Богуславская В. Ф. Методы противодействия экстремизму этноконфессиональной направленности: основные направления практической работы // Российский психологический журнал. - 2010. T. 7. - № 5-6. - С. 17-22.

2. Аллахвердиев К. Этноконфессиональный фактор национальной безопасности государств Кавказа // URL: http://www.ca-c.org/c-g/2008/ journal_rus/c-g-3/02.shtml

3. Звездина Г. П., Елагина М. Ю. Возможности современной школы в создании поликультурной образовательной среды // Этнопедагогика в современном обществе. Материалы Всероссийской научно-практической 
конференции, посвященной Году учителя. 19-21 октября 2010 г. - Грозный: Изд-во АН ЧР, 2010. - С. 304-310.

4. Звездина Г. П. Проблема формирования мировоззренческой безопасности как средства профилактики экстремизма в молодежной среде // Российский психологический журнал. - 2010. - Т. 7. - № 6. - С. 76-80.

5. Ипатова Л. П. Православная идентичность как персональный портрет / Гражданские, этнические и религиозные идентичности в современной России / Отв. ред. В. С. Магун. - М.: Изд-во Ин-та социологии РАН, 2006.

6. Карпухин Ю. Г. Армия, правоохранительные органы и религиозная безопасность // Вестник РГГУ. Серия «Право». - 2008. - № 5.

7. Киселёва Е. В. Современная российская семья в традиционно конфессиональном аспекте // Вестник славянских культур. - 2012. - Т. 1. № XXIII. - C. 37-43.

8. Косов Г. В. Политическая концепция Ислама: проблемы цивилизационного и политического анализа: монография. - Ставрополь, 2008. - С. 90.

9. Кураев А. Техника религиозной безопасности // URL: http://www.benjamin. ru/logos/kuraev/0003.html

10. Магомедов A. А. Социокультурная преемственность в сфере семейных отношений на Северном Кавказе // Вестник Ставропольского государственного университета. - 2009. - № 5. - С. 121-128.

11. Перепелкин Л. С., Стельмах В. Г. Этнокультурная безопасность России: общественные вызовы и государственная политика // Общественные науки и современность. - 2003. - № 3.

12. Подросток на перекрестке эпох: проблемы и перспективы социальнопсихологической адаптации подростков / Под ред. С. В. Кривцовой. Москва: Генезис, 1997. - 288 с.

13. Романова А. П., Мармилова О. В. Культурная безопасность как важнейший фактор национальной безопасности // Человек. Сообщество. Управление. - 2008. - № 2.

14. Романова А. П., Якушенков С. Н., Лебедева И. В., Топчиев М. С. Феноменология чужого в контексте культурной (этноконфессиональной) безопасности // Человек. Сообщество. Управление. - 2011. - № 1. - С. 44-56.

15. Сарапулов В. Н., Якупова В. Н. Безопасность человека и гуманитарные средства ее обеспечения (на примере космодрома Байконур) // URL: http://www.zpu-journal.ru/ezpu/1/Sarapulov\&lakupova

16. Стратегия национальной безопасности Российской Федерации до 2020 года (действующая редакция), утверждена Указом Президента России от 12 мая 2009 г. № 537 // КонсультантПлюс: нормативно-правовая база. - 2013. 
17. Топчиев М. С. Проблема конфессиональной безопасности: теоретикопонятийный анализ // Гуманитарные исследования. - 2012. - № 4 (44). C. 266-267.

18. Abakumova I. V., Kruteleva L. Ju. Life-sense Strategies as a Motivational-dynamic Characteristic of a Person // V Congress of Russian Psychological Society, Procedia - Social and Behavioral Sciences. - 2013. - 86. - pp. 35-41.

19. Kidder L. H., Kosuge N. Family-work in modern Japan: The reproduction of sons and mothers // Entitlements and the affectional bond. New York: Plenum. - 1992. 
[The psychology of formation of anti-terrorist values among students of the modern university: textbook (under the editorship of I. V. Abakumova, P. N. Ermakov)]. Moscow, KREDO Publ., 2013. 352 p.

14. Abakumova I. V., Kruteleva L. Ju. Tolerance in the Structure of Life-Sense Strategies of the Modern Youth / The 13th European Congress of Psychology, 2013, Stockholm, Sweden, 9-12 July 2013.

15. Grimsoltanova R. E., Grimsoltanova T. E. Value of myth and religious belief of young people in the conditions of post-conflict region // European Science and Technology: materials of the VIII international research and practice conference, Munich, October 16th-17th, 2014, pp. 291-296.

16. Grimsoltanova R. E. Psychology of religion and role of the phenomenon of possession in the student's environment of the Chechen Republic / World \& Science (May 1th, 2014). Brno, Chech Republic, 2014, pp. 152-157.

17. Grimsoltanova R. E. Rilevanza esperienze mistiche nelle regioni postconflitto // URL: http://www.ias-journal.org/archive/2014/january/ Grimsoltanova.pdf

18. Haber J., Jacob R., Spangler J. D. C. Dimensions of religion and their relationship to health // The International Journal for the Psychology of Religion, 2007, Vol. 17 (4), pp. 265-288.

19. Powell L. H., Shahabi L., Thoresen C. Religion and spirituality linkages to physical health // American Psychologist, 2003, Vol. 58, pp. 36-52.

20. Wuthnow R. How religious groups promote forgiving: a national study // J. Sci. Stud. Relig, 2000, Vol. 39, pp. 125-139.

\section{FAMILY VALUES AS A FACTOR OF ETHNO- CONFESSIONAL SAFETY}

\section{Zvezdina Galina Pavlovna Ismailov Kazbek Vaitovich}

The article substantiates the relevance of studying the problem of ethnoconfessional safety of a polycultural region in modern Russian society. The authors differentiate the concepts concerning the problem of ethno-confessional safety. They consider features of the presentation of concepts: confessional safety, religious safety, ethnocultural and ethnic safety, ethno-confessional safety. Threats of ethnoconfessional safety in a situation of uncertainty and instability of modern society are designated. The role of the family as a social institute transmitting values of culture and traditions of its ethnos is demonstrated. Results of the empirical study 
of family values of married couples of various ethnic origins living in conditions of the polycultural region (the Chechen Republic) are presented. Features of values of a modern family, depending on ethnic origin (Russians, Chechens, mixed families), in the context of ethno-confessional safety are distinguished and described.

The authors have revealed that values of wellbeing (to have a good job and a good family, health, to be loved) are significant for families of ethnic Russians. The majority of respondents stated the necessity of supporting national traditions, to instill national values and traditions in the children. It is established that in the mixed families the most part of respondents of both sexes noted that it is important to keep national traditions and develop national culture, to impart national values and traditions to children, to lead a spiritual life; the system of respondents' estimates vary between high and above average. The authors have revealed that in ethnic Chechen families they note that it is importance to impart to their children national traditions forming and supporting the feeling of unity at the level of ethnos, community, family, enabling an individual to realize his/her ethnic origin preserving centuries-old value guidelines and attitudes.

Keywords: polycultural region, confessional safety, religious safety, ethnoconfessionality, ethnic safety, ethno-confessional safety, family values, safety values.

\section{References}

1. Abakumova I. V., Boguslavskaia V. F. Metody protivodeistviia ekstremizmu etnokonfessional'noi napravlennosti: osnovnye napravleniia prakticheskoi raboty [Methods of counteraction to extremism of an ethno-confessional orientation: main directions of practical work]. Rossiiskii psikhologicheskii zhurnal - Russian Psychological Journal, 2010, V. 7, no. 5-6, pp. 17-22.

2. Allakhverdiev K. The ethno-confessional factor of national security of the states of the Caucasus. Available at: http://www.ca-c.org/c-g/2008/ journal_rus/c-g-3/02.shtml

3. Zvezdina G. P., Elagina M. lu. Vozmozhnosti sovremennoi shkoly v sozdanii polikul'turnoi obrazovatel'noi sredy [Possibilities of the modern school in creation of the polycultural educational environment]. Etnopedagogika v sovremennom obshchestve. Materialy Vserossiiskoi nauchno-prakticheskoi konferentsii, posviashchennoi Godu uchitelia [Proc. the All-Russian ScientificPractical Conference "Ethnopedagogics in modern society"]. Grozny, Academy of Science of the Chechen Republic Publ., 19-21 October, 2010, pp. 304-310.

4. Zvezdina G. P. Problema formirovaniia mirovozzrencheskoi bezopasnosti kak sredstva profilaktiki ekstremizma v molodezhnoi srede [The problem of forming the world outlook safety as the prevention of extremism in the youth 
environment]. Rossiiskii psikhologicheskii zhurnal - Russian Psychological Journal, 2010, V. 7, no. 6, pp. 76-80.

5. Ipatova L. P. Pravoslavnaia identichnost' kakpersonal'nyi portret/Grazhdanskie, etnicheskie i religioznye identichnosti v sovremennoi Rossii [Orthodox identity as a personal portrait. Civil, ethnic and religious identities in modern Russia]. Moscow, Institute of Sociology of the Russian Academy of Sciences Publ., 2006.

6. Karpukhin lu. G. Armiia, pravookhranitel'nye organy i religioznaia bezopasnost' [Army, law enforcement bodies and religious safety]. Vestnik RGGU. Seriia "Pravo» - Russian State University for the Humanities Bulletin. "Right" Series, 2008, no. 5.

7. Kiseleva E. V.Sovremennaia rossiiskaia sem'ia v traditsionno konfessional'nom aspekte [A modern Russian family in a traditionally confessional aspect]. Vestnik slavianskikh kul'tur - Bulletin of Slavic Cultures, 2012, V. 1, no. XXIII, pp. 37-43.

8. Kosov G. V. Politicheskaia kontseptsiia Islama: problemy tsivilizatsionnogo i politicheskogo analiza: monografiia [The political conception of Islam: problems of the civilization and political analysis: monograph]. Stavropol, 2008, 90 p.

9. Kuraev A. The technique of religious safety. Available at: http://www. benjamin.ru/logos/kuraev/0003.html

10. Magomedov A. A. Sotsiokul'turnaia preemstvennost' v sfere semeinykh otnoshenii na Severnom Kavkaze [Sociocultural continuity in the sphere of family relations in the North Caucasus]. Vestnik Stavropol'skogo gosudarstvennogo universiteta - Stavropol State University Bulletin, 2009, no. 5, pp. 121-128.

11. Perepelkin L. S., Stel'makh V. G. Etnokul'turnaia bezopasnost' Rossii: obshchestvennye vyzovy i gosudarstvennaia politika [Ethnocultural safety of Russia: public challenges and state policy]. Obshchestvennye nauki i sovremennost' - Social Sciences and the Present, 2003, no. 3.

12. Podrostok na perekrestke epokh: problemy i perspektivy sotsial'nopsikhologicheskoi adaptatsii podrostkov [A teenager at a crossroads of epoches: problems and prospects of social-psychological adaptation of teenagers]. Moscow, Genezis Publ., 1997, 288 p.

13. Romanova A. P., Marmilova O. V. Kul'turnaia bezopasnost' kak vazhneishii faktor natsional'noi bezopasnosti [Cultural safety as the most important factor of national security]. Chelovek. Soobshchestvo. Upravlenie - A Person. Community. Management, 2008, no. 2.

14. Romanova A. P., lakushenkov S. N., Lebedeva I. V., Topchiev M. S. Fenomenologiia chuzhogo v kontekste kul'turnoi (etnokonfessional'noi) 
bezopasnosti [Phenomenology of the stranger in the context of cultural (ethno-confessional) safety]. Chelovek. Soobshchestvo. Upravlenie - A Person. Community. Management, 2011, no. 1, pp. 44-56.

15. Sarapulov V. N., lakupova V. N. The person's safety and humanitarian means of its ensuring (on the example of the Baikonur Cosmodrome). Available at: http://www.zpu-journal.ru/ezpu/1/Sarapulov\&lakupova

16. Strategiia natsional'noi bezopasnosti Rossiiskoi Federatsii do 2020 goda (deistvuiushchaia redaktsiia), utverzhdena Ukazom Prezidenta Rossii ot 12 maia 2009 g. № 537 [The strategy of national security of the Russian Federation till 2020 (current edition) approved by the decree of the President of Russia on May 12, 2009, no. 537]. Konsul'tantPlius: normativno-pravovaia baza - ConsultantPlus: Normative-Legal Base, 2013.

17. Topchiev M. S. Problema konfessional'noi bezopasnosti: teoretiko-poniatiinyi analiz [The problem of confessional safety: theoretical-conceptual analysis]. Gumanitarnye issledovaniia - Humanitarian Researches, 2012, no. 4 (44), pp. 266-267.

18. Abakumova I. V., Kruteleva L. Ju. Life-sense Strategies as a Motivationaldynamic Characteristic of a Person //V Congress of Russian Psychological Society, Procedia - Social and Behavioral Sciences, 2013, 86, pp. 35-41.

19. Kidder L. H., Kosuge N. Family-work in modern Japan: The reproduction of sons and mothers // Entitlements and the affectional bond. New York: Plenum, 1992.

\title{
ON THE ISSUE OF STRATEGIES OF OVERCOMING PSYCHOLOGICAL BARRIERS
}

\author{
Osipova Alla Anatolyevna \\ Prokopenko Maxim Vladimirovich
}

The article deals with the problem of strategies of overcoming psychological barriers. Various typologies of strategies of overcoming psychological barriers are the subject of research. A psychological barrier is a certain intrapersonal obstacle which overcoming leads to qualitative transformation of both the person's activity and his/her personality (K. D. Ushinskii, S. L. Rubinshtein, B. G. Anan'ev). Emergence of a psychological barrier is treated by a number of authors as a certain critical situation which may have either constructive solutions or various destructions (N. A. Podymov, $R$. Kh. Shakurov). Domestic and foreign psychological literature demonstrates various approaches to ways of overcoming a crisis situation: metacognitive, cognitive, socio-affective. Strategies of overcoming are studied at two levels: situational and 